\title{
Advantages and Limitations of Intracoronary Ultrasound for the Assessment of Vascular Dimensions
}

\author{
CARLO DI MARIO, M.D., Ph.D., JAVIER ESCANED-BARBOSA, M.D.. JOSE BAPTISTA. M.D., \\ JÜRGEN HAASE, M.D., YUKIO OZAKI, M.D., Ph.D., JOS R.T.C. ROELANDT, M.D.. PH.D., \\ and PATRICK W. SERRUYS, M.D.. PH.D.
}

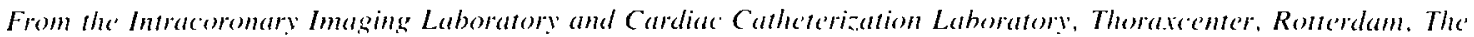
Netherlands

\section{Introduction}

Quantitative angiography has been used to validate the accuracy of the measurement obtained with the early intravascular ultrasound catheters. ${ }^{1-3}$ In more recent reports ${ }^{4-12}$ it was suggested that intravascular ultrasound can be superior to quantitative angiography in the assessment of complex lesions (eccentric stenoses, asymmetric lesions, vascular dissections). In this article, advantages and limitations of the two techniques in the assessment of vascular dimensions are discussed based on the results reported in the literature and of our experience in 94 patients with coronary artery disease.

\section{Previous Studies Comparing Intravascular Ultrasound and Angiography for the Assessment of Vascular Dimensions}

The results of 11 clinical studies in which quantitative angiography and intravascular ultrasound were compared are summarized in Table 1. Differences in equipment and methods of analysis limit the comparison and interpretation of data.

Address for reprints: Dr. Patrick W. Serruys, Thoraxcenter, Erasmus University. Room Ee 2332. Dr Molewaterplein 40. 3015 GD Rotterdam. The Netherlands. Fax: 31104633096.
Linear regression analysis is most commonly used as a statistical test in these studies. However, a regression coefficient close to 1 is not sufficient to conclude that the two techniques provide similar quantitative measurements. ${ }^{13}$ The mean difference of the paired measurements and indexes of dispersion along the line of identity are more meaningful parameters, but are not always reported. With the exception of the study by Tobis et al. ${ }^{6}$ the results indicate that there is a good correlation between intravascular ultrasound and angiographic measurements in normal or moderatey diseased segments. In general, larger cross-sectional areas were measured with intravascular ultrasound than with angiography. ${ }^{6.8 .9 .11 .12}$ A major limitation for a precise comparison is that the measurement of the same arterial cross-section is difficult, particularly when a major change of vascular cross-sectional area occurs in a very short segment. An angiogram of sufficient quality to be quantitatively analyzed cannot be obtained during the echographic measurements since the catheter positioned in the stenosis causes a severe arterial occlusion. limiting the distal opacification. In eccentric lesions or lesions treated with balloon angioplasty a poor correlation and a large scatter of the paired measurements was found immediately after balloon dilatation. After angioplasty, Tobis et al. ${ }^{6}$ observed that the cross-sectional areas measured with intracoronary ultrasound were up to $50 \%$ larger than the corresponding angiographic cross- 
DI MARIO, ET AL.

Table 1. Quantitative Angiography vs Intravascular Ultrasound: Clinical Comparative Studies

\begin{tabular}{|c|c|c|c|c|c|c|}
\hline Authors & Patients & Examined Arteries & $" r "$ & SEE & $\begin{array}{c}\text { Mean } \\
\text { Difference }\end{array}$ & $\begin{array}{c}\% \\
\text { Difference }\end{array}$ \\
\hline Davidson et al.: & $\begin{array}{l}21 \text { patients } \\
\text { undergoing cardiac } \\
\text { catheter }\end{array}$ & femoroiliac arteries & 0.97 & 1.83 & - & - \\
\hline Sheikh et al. ${ }^{3}$ & $\begin{array}{l}15 \text { patients } \\
\text { undergoing cardiac } \\
\text { catheter }\end{array}$ & femoral arteries & 0.95 & 0.91 & - & - \\
\hline The et al. ${ }^{*}$ & $\begin{array}{l}8 \text { patients undergoing } \\
\text { cardiac catheter }\end{array}$ & femoroiliac arteries & 0.96 & 0.47 & - & - \\
\hline Bartorelli et al. 5 & $\begin{array}{l}8 \text { patients undergoing } \\
\text { cardiac catheter }\end{array}$ & $\begin{array}{l}\text { normal common femoral } \\
\text { arteries }\end{array}$ & 0.96 & - & $0.3 \mathrm{~mm}$ & $4 \%$ \\
\hline Tobis et al." & $\begin{array}{l}27 \text { CAD patients } \\
\text { undergoing PTCA }\end{array}$ & $\begin{array}{l}\text { normal sites } \\
\text { stenosis post-PTCA }\end{array}$ & $\begin{array}{l}0.26 \\
0.18\end{array}$ & - & $\begin{array}{l}2.1 \mathrm{~mm}^{2} \\
1.7 \mathrm{~mm}^{2}\end{array}$ & $\begin{array}{l}30 \% \\
51 \%\end{array}$ \\
\hline Nissen et al. & $\begin{array}{l}8 \text { normal subjects } \\
43 \text { CAD patients }\end{array}$ & $\begin{array}{l}\text { normal coronaries } \\
\text { coronary arteries (all sites) } \\
\text { eccentric lesions }\end{array}$ & $\begin{array}{l}0.92 \\
0.86 \\
0.77\end{array}$ & $\begin{array}{l}0.21 \\
0.43 \\
0.77\end{array}$ & $\begin{array}{r}-0.05 \mathrm{~mm} \\
0.05 \mathrm{~mm} \\
0.06 \mathrm{~mm}\end{array}$ & $\begin{array}{l}1 \% \\
2 \% \\
2 \%\end{array}$ \\
\hline Werner et al. & 14 CAD patients & $\begin{array}{l}\text { normal sites } \\
\text { stenosis post-PTCA }\end{array}$ & $\begin{array}{l}0.86 \\
0.48\end{array}$ & - & - & - \\
\hline St. Goar et al. ${ }^{y}$ & $\begin{array}{l}20 \text { cardiac transplant } \\
\text { recipients }\end{array}$ & $\begin{array}{l}\text { normal coronaries } \\
\text { (angiographically) }\end{array}$ & 0.86 & 0.07 & $0.04 \mathrm{~mm}$ & $12 \%$ \\
\hline Jain et al. ${ }^{10}$ & 6 CAD patients & $\begin{array}{l}\text { Saphenous vein bypass grafts } \\
\text { (pre/post-PTCA) }\end{array}$ & 0.96 & - & - & - \\
\hline Hodgson et al." & $\begin{array}{l}\text { 34 CAD patients } \\
\text { undergoing PTCA }\end{array}$ & $\begin{array}{l}\text { reference segment } \\
\text { stenosis post-PTCA }\end{array}$ & $\begin{array}{l}0.77 \\
0.63\end{array}$ & - & - & - \\
\hline Haase et al. ${ }^{12}$ & $20 \mathrm{CAD}$ patients & stenosis post-PTCA & 0.53 & - & $2.3 \mathrm{~mm}^{2}$ & - \\
\hline
\end{tabular}

$\mathrm{CAD}=$ coronary artery disease $\mathrm{PTCA}=$ percutaneous transluminal coronary angioplasty.

sectional areas calculated assuming a circular mode.

\section{Percent Diameter and Cross-Sectional Area Stenosis: Which Technique Provides the Correct Measurements?}

The use of different reference measurements for the calculation of relative vascular dimensions with quantitative angiography and intravascular ultrasound may explain the large discordance between the results obtained with the two techniques (Fig. 1). Reference diameter and crosssectional area are measured in an angiographically normal segment of the vessel with quantitative angiography. In muscular arteries intravascular ultrasound allows a direct measurement of the area inside the internal elastic lamina, the so-called original lumen area which is equal to the sum of lumen and plaque area. This area is used as a reference in intravascular ultrasound. Intimal thickening is often present in angiographically normal reference segments (Fig. 2). Furthermore, a compensatory enlargement of the vessel is almost invariably present at the stenotic site, as confirmed also in recent studies with intracoronary ultrasound. ${ }^{14}$ These reasons explain why the angiographic reference lumen cross-sectional area is smaller than the ultrasonic reference area $^{15}$ so that less severe percent diameter and cross-sectional area stenosis will be calculated with quantitative angiography than with intravascular ultrasound (Fig. 3). In Figure 1, in the presence of a $1 / 2-\mathrm{mm}$ thick intimal lesion in the reference segment, a major difference is observed in percent diameter and cross-sectional area stenosis between quantitative angiography and intravascular ultrasound.

Percent diameter and cross-sectional area stenosis are physiologically important parameters and are major determinants of the pressure drop 


\section{VASCULAR DIMENSIONS BY INTRACORONARY ULTRASOUND}

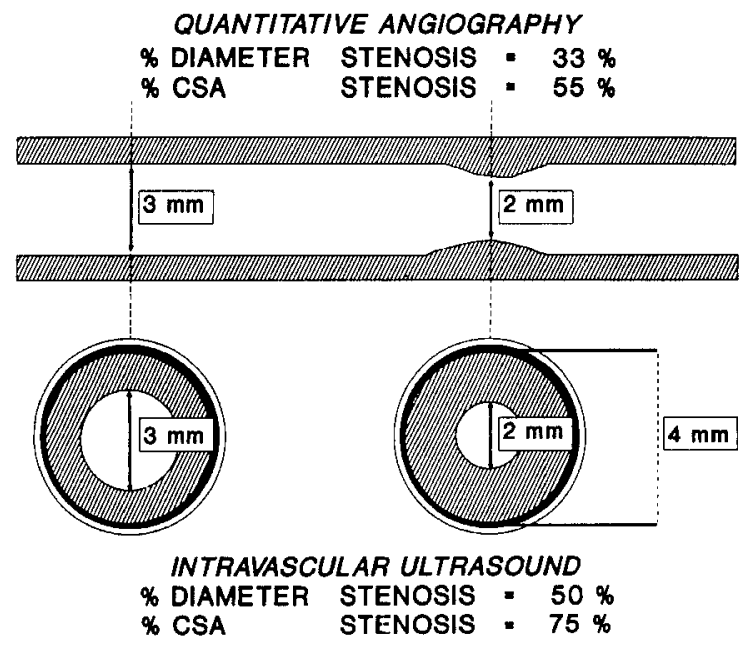

Figure 1. Calculation of percent diameter and cross-sectional area stenosis based on intravascular ultrasound and quantitative angiographic measurements. The reference lumen diameter is measured with quantitative angiography in the normal segments of the vessel while intravascular ultrasound directly measures the thickness of the atherosclerotic plaque at the stenosis site. In the presence of compensatory enlargment of the stenotic site or, as in this example, of a diffuse concentric intimal thickening involving also the angiographic reference segment, the intravascular ultrasound reference diameter. traced within the black band representing the muscular media, is larger than the angiographic reference diameter. As a result the angiographically moderate percent stenosis is considered more severe, "significant" according to the normally used criteria ( $\geq 50 \%$ diameter stenosis and $\geq 75 \%$ cross-sectional area stenosis) with intravascular ultrasound.

across a stenosis. ${ }^{16}$ However, the results obtained from animal models of acute external constriction of normal vessels ${ }^{17}$ cannot be simply applied to the percent lumen reduction measured with quantitative angiography. Harrison et al. ${ }^{18}$ showed that the stenosis related impairment of postocclusion reactive hyperemia cannot be predicted based on the coronary angiographic assessment of percent diameter and cross-sectional area stenosis. Awareness of these drawbacks has already contributed to focus the interest in the measurement of absolute rather than relative lumen stenosis in quantitative angiography. ${ }^{19}$ Intravascular ultrasound can directly measure plaque area and avoid the use of a reference measurement in a potentially diseased segment of the vessel. However, such reference area does not necessarily reflect the physiologically ideal vas- cular dimension because of the already mentioned compensatory enlargement. In particular the presence of a crescentic plaque with an outward remodeling of the vessel is likely not to influence the dimension of the vascular lumen. The presence of a reduction of the "ideal" dimension of lumen cross-sectional area is more difficult to be judged in the presence of a diffuse circular ring of intimal thickening (Fig. 2) ${ }^{20}$ Therefore the assessment of the physiological significance of a vascular stenosis requires different approaches such as the measurement of transstenotic velocity increase or of the pressure drop at maximal hyperemia across the stenosis or the calculation of coronary flow reserve based on angiographic or Doppler measurements.

\section{Advantages of Intravascular Ultrasound}

Advantages and disadvantages of intravascular ultrasound versus angiography are summarized in Table 2 .

No Calibration is Required. For angiography the measurement of a radiopaque structure of known dimension is required for calibration. When the tip of the catheter is used as a scaling device, possible sources of error are off-plane position of the catheter and the examined vessel, tapering of the catheter at the distal end, and discordance between true catheter diameter and diameter reported by the manufacturer. ${ }^{19.21}$ Furthermore, calibration must be repeated for every angiographic view. A potentially more precise, but even more cumbersome approach is the geometric correction for beam divergence, based on the measurement of the distances between $x$-ray source, imaged object, and image amplifier (isocenter technique). ${ }^{22}$

The measurement of a distance with ultrasound is based on the wavelength of the ultrasound beam and the velocity of sound in the medium. When the instrument is calibrated for the ultrasound speed in blood $(1,560 \mathrm{~m} / \mathrm{sec})$ a negligible overestimation occurs when saline is injected to replace the more echogenic blood and delineate the intimal contour.

Instantaneous Measurements are Available. Recently introduced digital angiographic equipment 


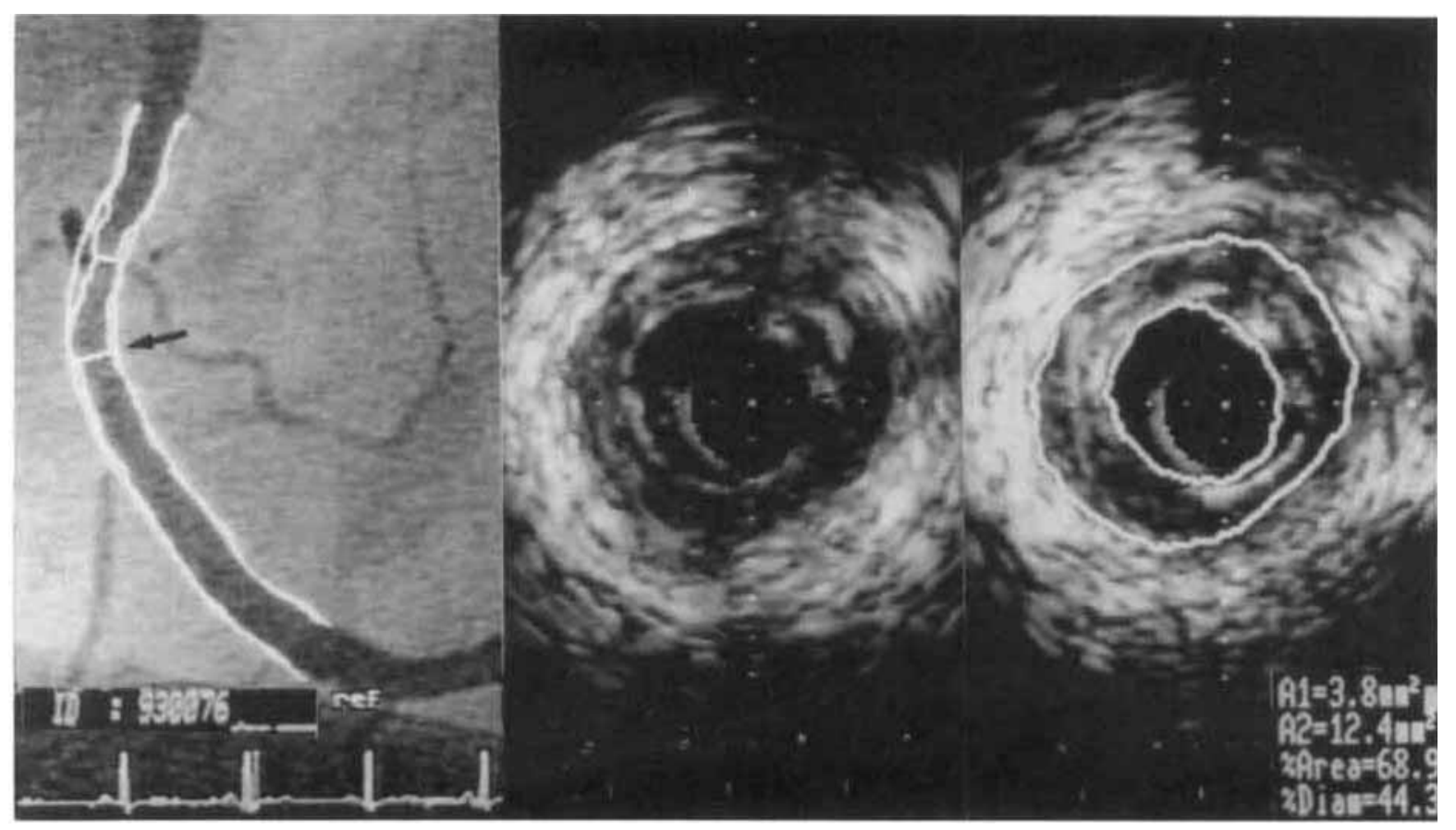

Figure 2. Digital angiogram of a right coronary artery with the reference diameter positioned at the site examined with intracoronary ultrasound. Note that in this angingraphically normal reference segment intracoronary ultrasound shows the presence of a concentric plaque inducing a $44 \%$ diameter stenosis. Calibration: $0.5 \mathrm{~mm}$.

allows the performance of on-line measurements of vascular dimensions. As a consequence, quantitative angiography can be used for guidance and immediate evaluation of interventional procedures. The time required for the analysis, however. is still considerable when compared to the really instantaneous measurement available with ultrasound.

No Contrast Medium Required: A Continuous Monitoring is Possible. Angiography requires the injection of contrast material to delineate the vascular lumen. As a consequence, angiography can- not be used for a continuous monitoring of vascular dimension. Other disadvantages of the use of contrast medium are the modification of the intraluminal pressure during the forceful contrast injection and the vasoactive properties of these agents.

Intravascular ultrasound allows a continuous real-time measurement of vascular dimensions, a great potential advantage for monitoring interventions and assessment of the effects of vasoactive agents on vascular dimensions and $d y-$ namics..$^{23}$

Figure 3. I A) Cineangiogram after automatic contour detection showing a severe proximal stenosis of the left anterior descending coronary artery (left panel) and a regular lumen (ca loci residual diameter stenosis) after implantation of a Gianturco Roubin stent (right panel). (B) Liltrasonic cross-sectional area in the most severe stenotic segment before angioplasty (left panel), after a predilatation with a $3.0-\mathrm{mm}$ angioplasty balloon (mid-panel), and after implantation of a $3.0-\mathrm{mm}$ Gianturco Roubin stent (right panell. The lower panels show the same ultrasonic cross-sections after on-line manual tracing of the lumen and plaque contours. Note that a similar plaque area is present before dilatation and after balloon dilatation and stent implantation $\left(12.2 \mathrm{~mm}^{2}\right.$ and $11.1-11.9 \mathrm{~mm}^{2}$, respectively) despite the large increase in lumen area (from $2.1 \mathrm{~mm}^{2}$ before treatment $104.6 \mathrm{~mm}^{2}$ and $6.6 \mathrm{~mm}$. after balloon dilatation and stent implantition. respectively). The increase in lumen area after balloon angioplasty is the consequence of multiple irregular fractures of the plaques while a regular circular luminal cross-sectional area is present after stent implantation. Calibration: $0.5 \mathrm{~mm}$. 
VASCULAR DIMENSIONS BY INTRACORONARY ULTRASOUND
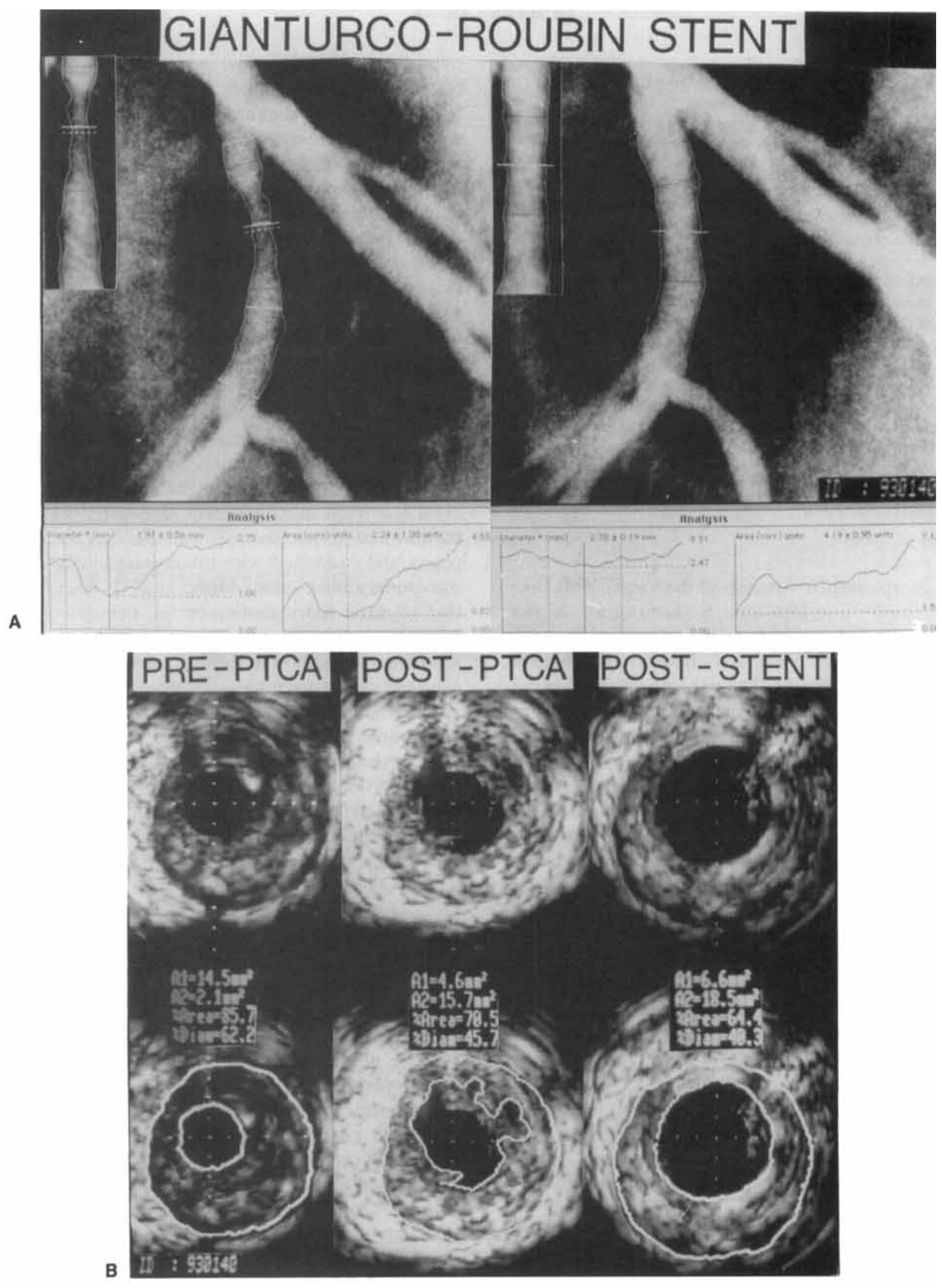

Figure 3 
DI MARIO. ET AL.

Table 2. Advantages and Limitations of Intrawascular Ultrasound for Quantitative Assessment of Vascular Dimensions

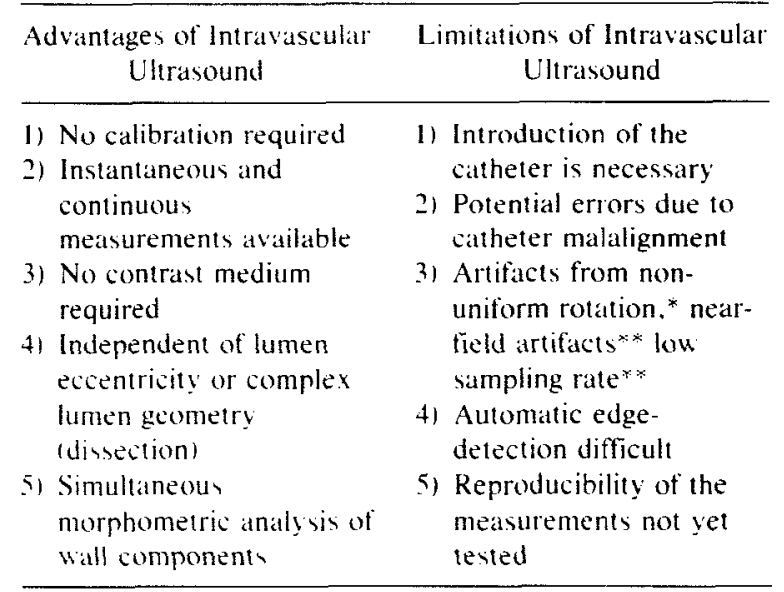

* single element mechanically rotating systems: * multiele ment synthetic aperture array systems.

Morphometric Analysis of the Vessel Wall. Angiography provides only a shadowgram of the vascular lumen. so that the presence of vascular lesions is derived indirectly from irregularities of the luminal contour. The only information on the composition of atherosclerotic plaques concerns the presence of fluoroscopically visible vessel wall calcification. Pathology studies and, more recently, the application of intraoperative and intravascular high frequency ultrasound have shown that coronary arteries undergo a progressive enlargement in relation with increases in plaque area. so that a reduction of lumen area is delayed until the atherosclerotic lesion occupies more than $40 \%$ of the area circumscribed by the internal elastic lamina ${ }^{14.24 .25}$ (Fig. 4). These findings explain why angiographically normal arterial segments may show an extensive atherosclerotic involvement at autopsy and upon direct surgical inspection. Several reports have confirmed that intravascular ultrasound can detect atherosclerotic changes in angiographically normal segments ${ }^{4.9}$ (Fig. 2). Furthermore, intravascular ultrasound displays the components of the atherosclerotic plaque with a different intensity proportional to their backscatter power, ${ }^{26-2 x}$ allowing their qualitative differentiation. In vitro studies have shown that intravascular ultrasound has a high sensitivity and specificity in the detec- tion of intimal lesions and in the differentiation between fibrous, calcific, and lipid containing plaques. ${ }^{29}$ Plaque thickness can be measured, especially if the presence of an echographically hypoechoic medial layer facilitates the delineation of plaque contours and if no shadowing or attenuation from plaque components is present. ${ }^{29}$

The possibility to provide information on plaque morphology and dimension at the same time makes intravascular ultrasound an ideal technique for the assessment of the mechanism of the different coronary interventions and the modalities of progression/regression of the atherosclerotic plaque. Wall stretching and wall dissection have been reported as the main operative mechanism of balloon angioplasty in both coronary $^{30}$ and peripheral arteries. ${ }^{31}$ A significant plaque compression (absolute reduction of plaque area) has been more recently reported. ${ }^{32}$ In 18 coronary stenoses treated with balloon angioplasty and examined with three-dimensional intracoronary ultrasound, Mintz et al. ${ }^{33}$ observed that an axial redistribution of the plaque away from the narrowest cross-sectional area, without significant changes in the total plaque volume. An example of the usefulness of three-dimensional reconstruction of intracoronary ultrasound in the assessment of the results of coronary interventions is shown in Figure 5.

Standard methods used in quantitative angiography for the assessment of regression of atherosclerosis are the measurement of mean luminal area and severity of edge irregularities ${ }^{34}$ (roughness profile). A long-term follow-up of large cohorts of patients is necessary to show a statistically significant trend toward regression or delayed progression of plaques in peripheral ${ }^{35}$ and coronary ${ }^{36.37}$ atherosclerotic disease.

Intravascular ultrasound has the potential of detecting atherosclerotic wall disease in the prestenotic phase and allows the measurement of both lumen and plaque area. ${ }^{38}$ Dietary and pharmacological interventions may cause a more rapid and complete regression of the vascular changes in the early "prestenotic" phase of atherosclerosis rather than in the more advanced phases. ${ }^{39}$ Animal studies have shown that intravascular ultrasound can detect plaque progression earlier and more accurately than quantitative angiography. ${ }^{40-42}$ The possibility to differentiate 
VASCULAR DIMENSIONS BY INTRACORONARY ULTRASOUND

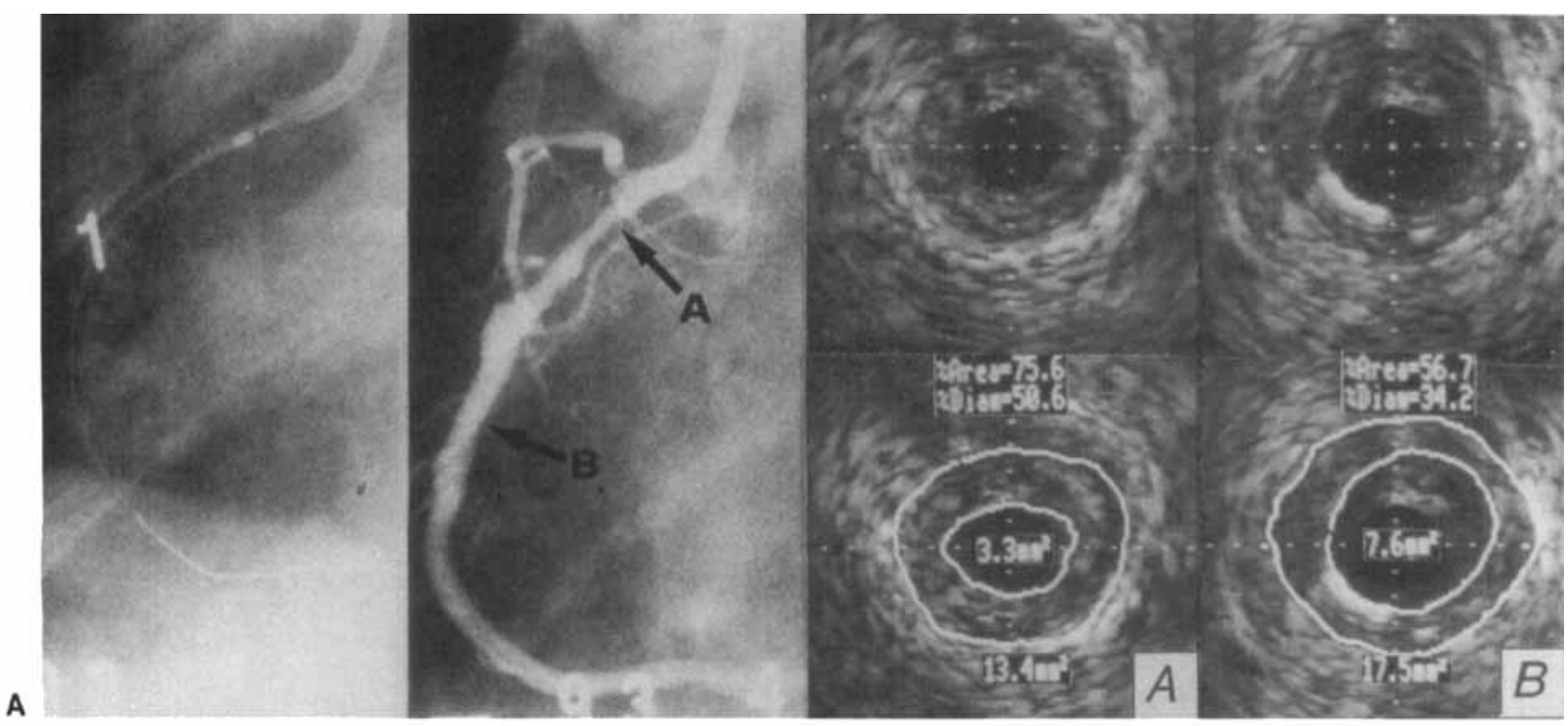

A

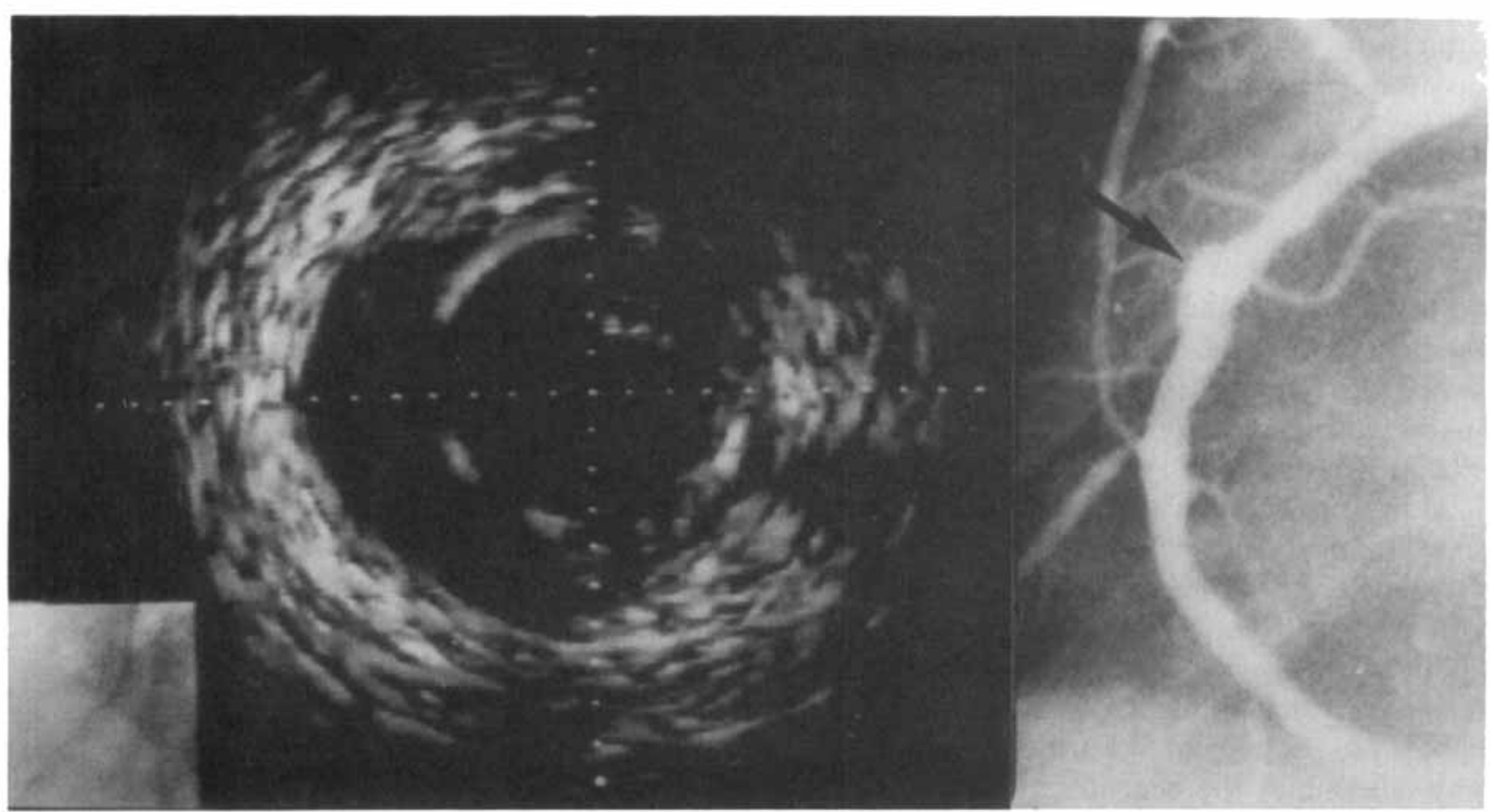

Figure 4. (A) Angiographic and intracoronary ultrasonic examination 4 months after stenting (Gianturco Roubin) of the midsegment of the right coronary artery. The ultrasonic cross-sections on the right (B) show the segment where the stent was implanted (note the highly echogenic wire. close to the arterial lumen. in the lower left corner). A de novo lesion was present in the proximal segment (A), with the presence of a large concentric plaque with a low echoreflectivity and without calcification. Note that the plaque area in $\mathrm{A}\left(10.1 \mathrm{~mm}^{2}\right)$ is similar to the plaque area in $\mathrm{B}\left(9.9 \mathrm{~mm}^{2}\right)$, despite the large difference in luminal cross-sectional area and percent cross-sectional area stenosis (76\% in position A vs $57 \%$, position B). (B) In the same artery after balloon dilatation of the proximal segment, a large echo-free area behind the stent wires and communicating with the arterial lumen (right panel) indicates a malapposition of the stent to the arterial wall in a segment of aneurysmatic dilatation (arrow in the cineangiogram in the right panel). Calibration: $0.5 \mathrm{~mm}$. 

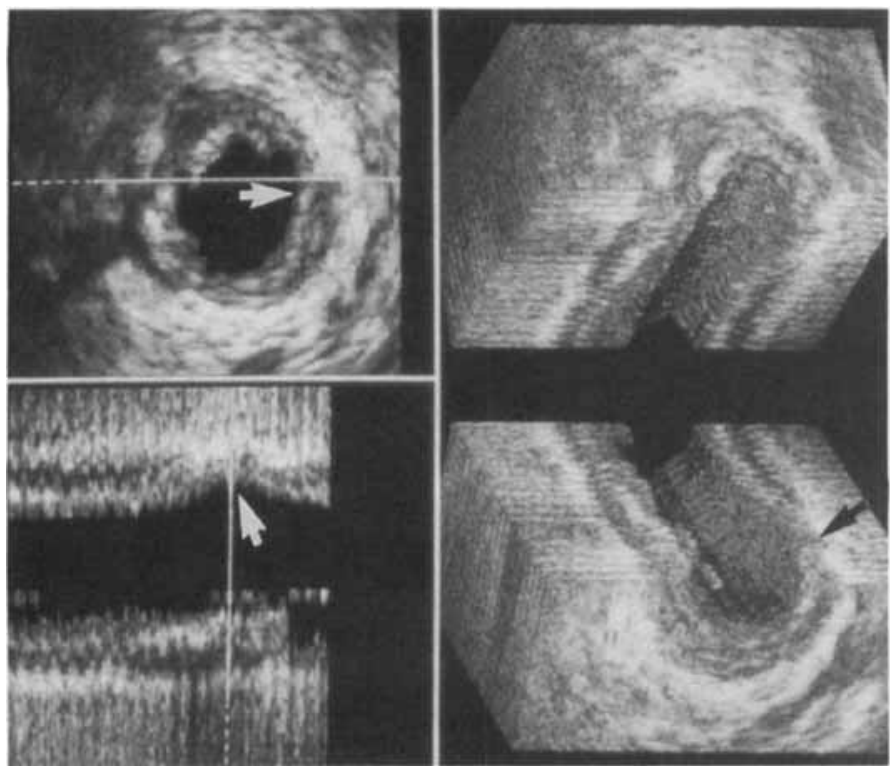

Figure 5. Proximal segment of the left circumflex artery examined immediately after directional coronary atherectomy. The position of the cut is clearly visible after three-dimensional reconstruction of the intravascular ultrasound images in the longitudinal format (arrowhead in the left lower panel) than in the image on the right, showing the arterial segment as two open hemicylinders (arrow). The position of the cut is not evident if only a single two-dimensional cross-section is considered (arrow in the area of plaque removal).

lipid plaques, potentially amenable to regression after interventions, from fibro-calcific plaques. less likely to respond to such an intervention ${ }^{43}$ is of particular interest.

Plaque Eccentricity. In most cases, with the use of multiple projections. an angiogram perpendicular to the maximal thickness of the plaque can be obtained. In $<50 \%$ of the cases. however, appropriate orthogonal projections, amenable to quantitative analysis, can be obtained to measure lumen area from its long and short axis when an elliptical area is present. ${ }^{44}$ Furthermore, angiography determines the eccentricity of a stenosis comparing the proximal and distal segments of the vessel. assumed as "normal" reference segments so that a misinterpretation is possible if the eccentric plaque involves also the reference segments (Fig. 6).

Intravascular ultrasound detects the eccentricity of the lesion from a direct measurement of the maximal and minimal thickness of the plaque. The eccentricity index calculated with intravascular ultrasound is independent from the characteristics of the contiguous segments. ${ }^{45}$ The advantage of the direct visualization of eccentric plaques is obvious in the guidance of percutaneous recanalization techniques that allow selective removal of atheromatous plaque. avoiding a potentially dangerous treatment in areas of thin, normal wall. ${ }^{46}$

Complex Lumen Geometry (Wall Dissection). Pathology studies have shown that splitting of the vessel wall is extremely frequent after balloon angioplasty and is one of the major mechanisms of effective lumen enlargement. ${ }^{47.48}$ Only large dissections are angiographically evident after balloon angioplasty. Several reports ${ }^{6.30-32.49-51}$ have confirmed that intravascular ultrasound is more sensitive than angiography in the detection of plaque rupture. The absence of echographically evident plaque rupture has been recently reported to increase the risk of restenosis. ${ }^{52}$ The quantitative measurement of residual stenosis early after balloon angioplasty is a poor indicator of the functional result of the procedure as assessed by coronary flow reserve $e^{53}$ and persistence of scintigraphic and electrocardiographic signs of reversible myocardial ischemia. Several reasons may explain these findings. In some cases. the comparison between echographic and 


\section{ECCENTRICITY INDEX}

INTRAVASCULAR ULTRASOUND

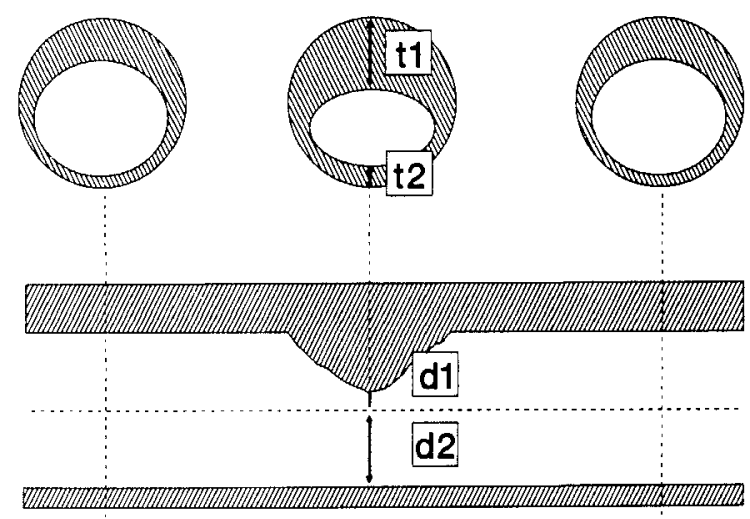

QUANTITATIVE ANGIOGRAPHY

Figure 6. Eccentricity index calculated with quantitative angiography and intravascular ultrasound. Intravascular ultrasound allows the direct assessment of the wall thickness so that the eccentricity index is based on the ratio between plaque thickness and thickness of the opposite wall. Quantitative angiography estimates the eccentricity of a plaque from the distance between the center of the lumen and the luminal contours at the site of the stenosis. In this example, however, the presence of a different thickness of the wall also in the angiographically normal segment induces an underestimation of the plaque eccentricity.

quantitative angiographic measurements suggests that an overestimation of the lumen available for blood passage may occur when a geometric technique (edge detection) is used (Fig. 7). Densitometric measurements have been suggested in order to overcome the limitations of edge detection in lesions of complex geometry (including stenosis postangioplasty and eccentric lesions). ${ }^{54}$ Densitometry, however, requires a homogeneous filling of the lumen with contrast and a perfect orthogonality of the $x$-ray beam to the vessel lumen, is highly dependent on the radiographic setting and modalities of film processing and cannot directly provide absolute measurements. ${ }^{55}$

\section{Limitations of Intravascular Ultrasound (Table 2)}

Necessity of Catheter Insertion. Intravascular ultrasound requires the examination with the echo-catheter of the entire vascular segments to be studied. Instrumentation of a coronary vessel is the current practice for all the interventional techniques. However, especially in the examination of the coronary arteries, the insertion of the echo-catheter increases the complexity and duration of the procedure and carries out a potential risk of complications. Recent improvements in catheter flexibility and miniaturization allow the examination of the proximal and middle coronary arteries in most patients. A possible limitation, however, concerns the examination of severe coronary stenosis before interventions, one of the most interesting potential applications of intravascular ultrasound. A quantitative angiographic study of large cohorts of candidates to balloon angioplast $y^{56}$ has shown that the measured minimal luminal diameter before balloon dilatation $(1.02 \pm 0.37 \mathrm{~mm})$ is similar to the diameter of the recently introduced second generation of catheters (from 3.5Fr to $4.3 \mathrm{Fr}$, equal to $1.15-1.4 \mathrm{~mm}$ ).

The intravascular ultrasound examination is facilitated after successful therapeutic interventions by the increased lumen diameter. However, recrossing large, unstable dissection flaps carries a potential risk of acute occlusion. Furthermore, a correct assessment of the real morphology of a complex spiral dissection and the consequent impairment to blood passage is difficult because it would require a three-dimensional reconstruction of the ultrasonic cross-sections ${ }^{57-61}$ and because the communication between true and false lumen is modified by the physical presence of the catheter. Proximal injection of saline or agitated contrast can help in delineating vessel lumen and in detecting the presence of stagnant blood flow. However, an effective injection through the proximal guiding catheter is not always possible while the relatively large ultrasound catheters are still in place.

Dropouts may occur in segments of dissected wall which are explored with an unfavorable angle of incidence of the ultrasound beam. ${ }^{62}$ In our experience, such complex artifacts are more frequent in peripheral than in coronary arteries, because in these latter small vessels the physical presence of the ultrasound catheter modifies the orientation of the dissected flap.

The combination of intravascular ultrasound imaging and balloon angioplasty or alternative de- 
DI MARIO. ET AL.

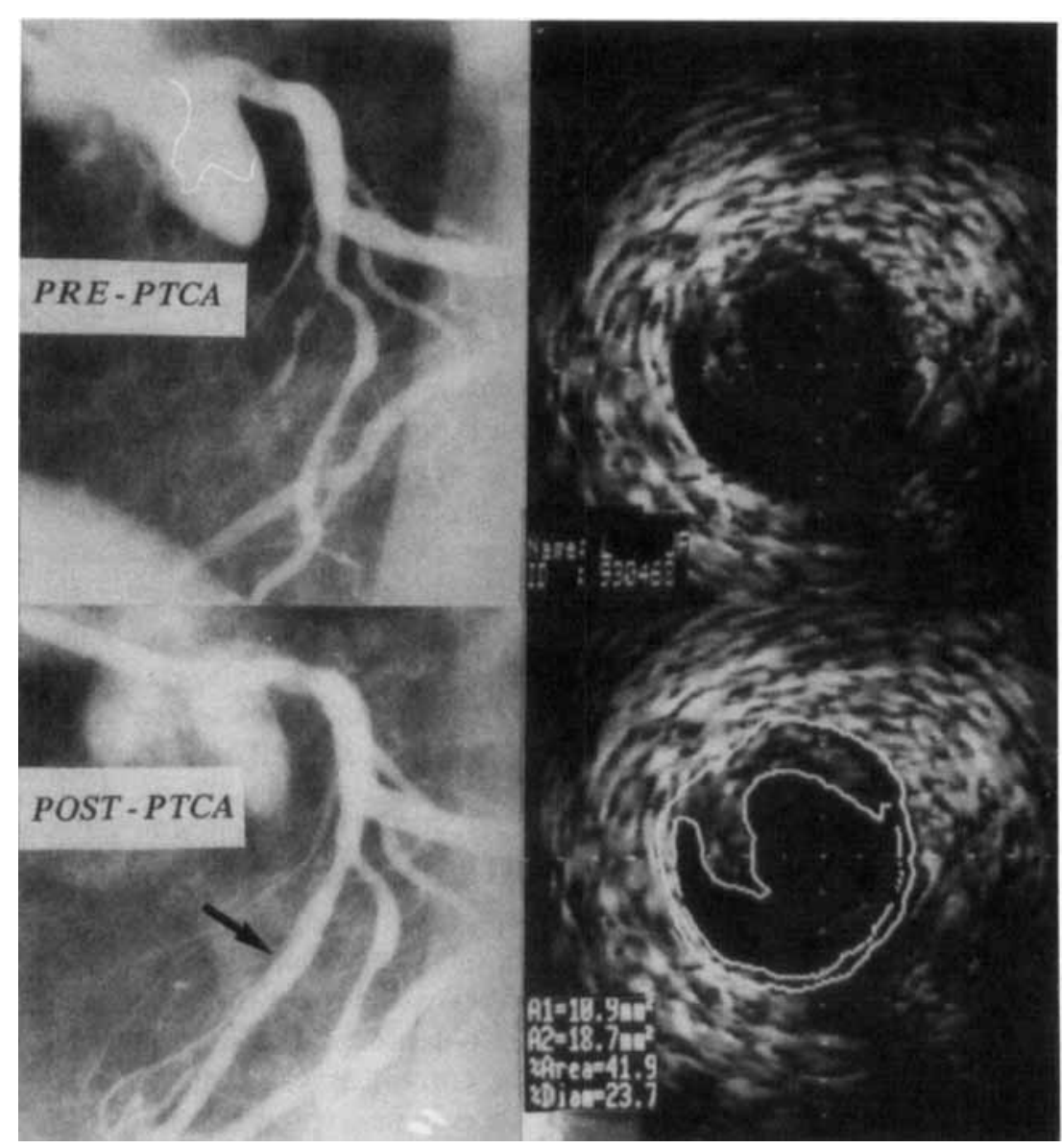

Figure 7. The upper right panel shows a subocclusive stenosis of the mid-segment of the left anterior descending coronary artery with a minimal anterograde flow. The lumen enlargment and the normalization of flow after dilatation with a $3.0-\mathrm{mm}$ balloon is evident in the lower right panel. where an arrow indicates a Type B dissection involving also the poststenotic segment. Note. in the panels on the left. the complex luminal crosssection after balloon dilatation. Note that the eccentric plaque has been dissected at the site of its insertion on the normal wall. The complex lumen after angioplasty cannot be correctly measured with angiography, even using multiple angiographic projections. Calibration: $0.5 \mathrm{~mm}$.

bulking techniques in the same catheter can facilitate the use of intravascular ultrasound before and after interventions and can allow continuous monitoring and guidance during the procedure. At present. however. only prototypes of catheters for directional atherectomy mounting ultrasound crystals are in the phase of preliminary clinical evaluation and in the already available echo-balloon catheters the transducer is mounted proximal to the balloon. ${ }^{63.64}$ This configuration maintains a low profile of the balloon and avoids the artifacts induced by the balloon membrane. but precludes the possibility of continuous assessment before, during, and immediately after balloon dilatation.

Catheter Malalignment. A central position of the catheter in the vessel lumen is not frequent in intravascular ultrasound. With a simple eccentricity of the catheter position. the echographic cross-section is still perpendicular to the long axis of the vessel so that no change in the measured area is expected. When the catheter is not only eccentric. but also nonparallel to the long axis of the vessel the vascular lumen is distorted, with an 


\section{VASCULAR DIMENSIONS BY INTRACORONARY ULTRASOUND}

angle dependent overestimation of the vascular lumen. In a tortuous artery the ultrasound catheter can assume an orientation nonparallel to the long axis of the vessel. Fortunately, the small size of the coronary arteries in comparison to the catheter diameter limits the practical relevance of this problem. ${ }^{9}$

Nonuniform Rotation, Near Field Artifact, Inadequate Sampling Rate. With mechanically rotating catheters, a 1:1 rotation of the ultrasound element (or mirror) can be impossible if the catheter is inserted in very tortuous vessels, resulting in a variable distortion of the ultrasound image. In the multielement systems these artifacts are not present. A limitation of these systems, however, is that the near field artifact is partially obscuring the structures close to the catheter. Artifacts can also result from the phasic changes of the position of the catheter inside the vessel throughout the cardiac cycle. A too low sampling rate can result in inability to accurately measure the systodiastolic changes of vascular dimensions.

Application of Automatic Measurements. Sophisticated techniques of edge detection or videodensitometry have been developed for quantitative angiography. ${ }^{65}$ The difference in brightness between the radiographic contrast filling the vascular lumen and the background facilitates the application of the proposed algorithms for computer-assisted automatic contour detection. In intravascular ultrasound, on the contrary, the relatively similar echoreflectivity of blood and of the underlying vessel wall is a potential obstacle to fully automatic measurements of lumen area. Manual redrawing of part of the lumen contours is frequently necessary, resulting in an increase variability of the results of the analysis. ${ }^{\text {to }} \mathrm{A}$ fully automatic technique, based on the measurement of the vessel wall displacement from a semiautomatic defined template image, has been developed at our institution and is currently used to measure the systo-diastolic changes of vascular dimensions. ${ }^{67}$

Reproducibility of the Measurements. Changes in vascular tone, variability of repeated measurements, modifications of radiographic projections and setting, cardiac and respiratory movements influence short- and long-term reproducibility of angiographic measurements, limiting the reliability of angiography in assessing the development of changes in vascular dimensions. Although intravascular ultrasound is less limited by these factors, accurate serial measurements are possible only when the echo-catheter is positioned exactly at the same site in the vessel, a trivial requirement which is practically very difficult to satisfy.

No Assessment of Blood Flow. Various angiographic techniques have been described which use the contrast medium as a marker of flow and calculate relative changes of blood flow based on contrast appearance time and/or on changes in the density of the myocardium. ${ }^{6 x-70}$ This principle is not applicable with the current intravascular ultrasound imaging catheters. An alternative ultrasound based technique is the measurement of the Doppler shift induced by the motion of the red blood cells to directly calculate blood flow velocity. Prototypes of combined imaging-Doppler catheters have been described ${ }^{71,72}$ and Doppler guidewires which can integrate the ultrasound imaging catheters are in current clinical use $\mathrm{s}^{73-75}$ (Fig. 8).

\section{Conclusions}

Intravascular ultrasound can accurately assess luminal dimensions and has potential advantages on quantitative arteriography in the presence of eccentric lesions and lumens of complex geometry. The application of this technique, however. increases duration, risk, complexity and cost of a conventional diagnostic or interventional procedure based on a purely angiographic quantitative assessment. In clinical practice, therefore. it seems unlikely that quantitative arteriography can be replaced by intravascular ultrasound ats a routine technique of measurement of luminal dimensions.

Intravascular ultrasound has a potential role as a research tool for the assessment of vessel $d y$ namics and effects of pharmacological interventions. The information concerning characteristics and composition of the atherosclerotic plaque is not available with angiography and makes intravascular ultrasound potentially more suitable than angiography for the follow-up of interventions aimed at the regression of atherosclerotic lesions. Improvements in catheter technology 


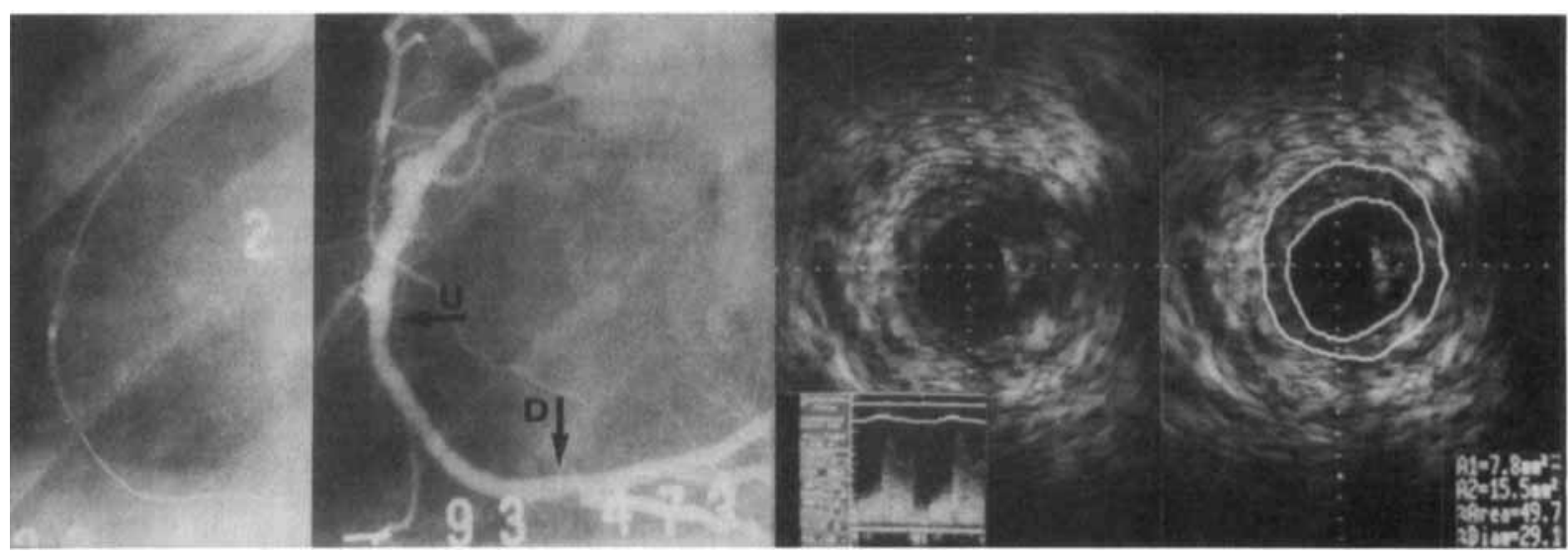

Figure 8. Same artery of Figure 4 after balloon dilatation. with the new position of the ultrasonic catheter documented in the cineframe without contrast in the left panel and indicated (U) in the corresponding cineangiogram. The position of the 0.014 in Doppler tipped guidewire is atso indicated with an arrow (D). Note that the Doppler signal and the ultrasonic cross-section are continuously and simultaneously displayed and recorded using a split-screen mode. The method allows a continuous phasic measurement of blood flow if the ultrasonic cross-sectional area is measured (right panel) and positioned at the site of the Doppler sample volume. Calibration intravascular ultrasound: $1 \mathrm{~mm}$ : catlibration Doppler: $120 \mathrm{~cm} / \mathrm{sec}$.

can make quantitative intravascular ultrasound a valuable tool for the correct planning and guidance of interventional procedures.

Acknowledsments. The author wish to thank the Medical and Technical Staff of the Cardiac Catheterization Laboratory. University Hospital Dijk zigt. Rotterdam for their contribution to the acquisition of the ultrasonic and angiographic images.

\section{References}

1. Nissen SE. Grines CL. Gurley JC. et al. Application of a new phased-array ultrasound imaging catheter in the assessment of vascular dimensions. In vivo comparison to cineangiography. Circulation: 1989: 81:660-666.

2. Davidion CJ. Sheikh KH. Harrison KJ. et al. Intravassular ultrasonography versus digital subtraction angiography: A human in vivo comparison of vessel size and morphology. J Am Coll Cardiol 1990: 16:633-636.

3. Sheikh KH. Davidson CJ. Kisslo KB. et al. Comparison of intravascular ultrasound. external ultrasound and digital angiography for evaluation of peripheral artery dimensions and morphology. Am J Cardiol 1991: 67: $817-822$.

4. The SKH. Gumenhoven EJ. Serruys PW. et al. Quantitative angiography vs intravascular ultrasound for the assessment of vascular dimensions and systo-diastolic changes. J Interven Cardiol 1992: 16:143-147.

5. Bartorelli AL. Neville RF. Keren G. et al. In vivo and in vitro intravascular ultrasound imaging. Eur Heart $\mathrm{J}$ 1992: 13:102-108.
6. Tobis JM. Mallery J. Mahon D, et al. Intravascular ultrasound imaging of human coronary arteries in vivo. Circulation 1991: 83:913-926.

7. Nissen SE, Gurley JC, Grines CL, et al. Intravascular ultrasound assessment of lumen size and wall morphology in normal subjects and patients with coronary artery disease. Circulation 1991: 84:1087-1099.

8. Werner GS. Sold G. Buchwald A. et al. Intravascular ultrasound imaging of human coronary arteries after percutaneous transluminal angioplasty: Morphologic and quantitative assessment. Am Heart J 1991: 122:212-220.

9. St. Goar FG. Pinto FJ. Alderman EL, et al. Intravascular ultrasound of angiographically normal coronary arteries: An in-vivo comparison with quantitative angiography. J Am Coll Cardiol 1991: 18:952-958.

10. Jain SP, Roubin GS, Nanda NC, el al. Intravascular ultrasound imaging of saphenous vein graft stenosis. Am J Cardiol 1992: 69:133-136.

II. Hodgson McJB. Reddy KG. Suneja R, et al. Intracoronary ult rasound imaging: Correlation of plaque morphology with angiography, clinical syndrome and procedural results in patients undergoing coronary angioplasty. J Am Coll Cardiol 1993; 21:35-44.

12. Haase J. Ozaki Y. Di Mario C. et al. Can intravascular ultrasound correctly assess the luminal dimensions of coronary artery lesions? A comparison with quantitative angiography. Eur Heart J (submitted for publication).

13. Bland JM. Altman DG. Statistical methods for assessing agreement between two methods of clinical measurement. Lancet 1987: 1:307-310

14. Hermiller JB. Tenaglia AN. Kisslo KB. et al. In vivo validation of compensatory enlargment of atherosclerotic coronary arteries. Am J Cardiol 1993; 71:665-668.

15. Davidson CJ. Tenaglia AN. Buller CE, et al. Coronary angiography underestimates post-interventional lesion stenosis and reference segment. (abstract) Circulation 1991: 84:11-437.

16. Young DF, Tsai FY. Flow characteristics in models of arterial stenosis. J Biomech 1973: 6:395-406. 


\section{VASCULAR DIMENSIONS BY INTRACORONARY ULTRASOUND}

17. Gould KL. Pressure-flow characteristics of coronary stenoses in unsedated dogs at rest and during coronary vasodilatation. Circ Res 1978; 43:242-251.

18. Harrison DG, White CW, Marcus ML, et al. The value of lesion cross-sectional area determined by quantitative coronary angiography in assessing the physiologic significance of proximal left anterior descending stenoses. Circulation 1984; 69:1111-1119.

19. Reiber JHC, Serruys PW. Quantitative coronary angiography. In: Marcus ML, Schelbert T, Skorton WA, et al., eds. Cardiac Imaging. A Companion to Braunwald's Heart Disease. Philadelphia: W.B. Saunders, 1991: 213-280.

20. Nissen SE, Gurley JC, Booth DC, et al. Mechanisms for false negative coronary angiography: Insights from intravascular ultrasound imaging. (abstract) J Am Coll Cardiol 1992; 19:140A.

21. Reiber JHC, Kooijman CJ, Serruys PW, et al. Assessment of dimensions and image quality of coronary contrast catheters from cineangiograms. Cath Cardiovasc Diag 1985; 11:521-531.

22. Gould LK. Quantitative coronary arteriography. In: Gould LK, ed. Coronary Artery Stenosis. New York, Amsterdam, London: Elsevier, 1991:93-107.

23. Wilson R, Di Mario C, Roelandt J, et al. Changes in large arteries compliance measured with intravascular ultrasound. (abstract) J Am Coll Cardiol 1992; 19:140A.

24. McPherson DD, Hiratzka LF, Sirna SJ, et al. Coronary artery remodeling studied by high frequency epicardial echocardiography: An early compensatory mechanism in patients with obstructive coronary atherosclerosis. J Am Coll Cardiol 1991; 17:79-86.

25. Nissen SE, Booth DC, Gurley JC, et al. Coronary remodelling in coronary artery disease: Intravascular ultrasound evidence of vessel expansion. (abstract) Circulation 1991; 84:II-437.

26. Gussenhoven EJ, Essed CE, Roelandt J, et al. Arterial wall characteristics determined by intravascular ultrasound imaging: An in vitro study. J Am Coll Cardiol 1989; 14:947-952.

27. Nishimura RC, Edwards WD, Warnes CA, et al. Intravascular ultrasound imaging: In vitro validation and pathologic correlation. J Am Coll Cardiol 1990; 16: 145-154.

28. Gussenhoven WJ, Frietman P, The SHK, et al. Assessment of medial thinning in atherosclerosis with intravascular ultrasound. Am J Cardiol 1992; 68:625-632.

29. Di Mario C, Serruys PW, Roelandt JRTC, et al. Detection and characterization of vascular lesions with intravascular ultrasound. J Am Soc Echocardiogr 1992; 5: $135-146$.

30. Tenaglia AN, Buller CE, Kisslo KB, et al. Mechanisms of balloon angioplasty and directional coronary atherectomy as assessed by intracoronary ultrasound. J Am Coll Cardiol 1992; 20:685-691.

31. The SHK, Gussenhoven EJ, Zhong Y, et al. Effect of balloon angioplasty on femoral artery evaluated with intravascular ultrasound imaging. Circulation 1992; 86: $483-493$.

32. Losordo DW, Rosenfield K, Pieczek A, et al. How does angioplasty work? Serial analysis of human iliac arteries using intravascular ultrasound. Circulation 1992; 86: 1845-1858.

33. Mintz G, Kovach JA, Park KS. Conservation of plaque mass: A volumetric intravascular ultrasound analysis of patients before and after percutaneous transluminal cor- onary angioplasty. (abstract) J Am Coll Cardiol 1993: 21:484A.

34. de Feyter PJ, Serruys PW, Davies MJ, et al. Quantitative coronary angiography to measure progression and regression of coronary atherosclerosis: Value, limitations, and implications for clinical trials. Circulation 1991; 84:412-423.

35. Blackenhorn DH, Azen SP, Crawford DW, et al. Effects of colestipol-niacin therapy on human femoral atherosclerosis. Circulation 1990; 83:438-447.

36. Greg Brown B, Albers JJ, Fisher LD, et al. Regression of coronary artery disease as a result of intensive lipidlowering therapy in men with high levels of apolipoprotein B. N Engl J Med 1980; 323:1289-1298.

37. Kane JP, Malloy MJ, Ports TA, et al. Regression of coronary atherosclerosis during treatment of familial hypercholesterolemia with combined drug regimens. J Am Med Assoc 1990; 3007-3012.

38. Pinto FJ, St. Goar FG, Popp RL, et al. In vivo correlation of intimal proliferation by intracoronary ultrasound with angiographic evidence of coronary artery progression. (abstract) J Am Coll Cardiol 1991; 19:300A

39. Armstrong ML, Heistad DD, Marcus ML, et al. Structural and hemodynamic responses of peripheral arteries of macaque monkeys to atherogenic diet. Atherosclerosis $1985 ; 5: 336-346$

40. Lassetter JE, Krall RC, Moddrelle DS, et al. Intravascular ultrasound detects plaque progression earlier and more accurately than quantitative angiography. (abstract) J Am Coll Cardiol 1991; 17:156A.

41. Lassetter JE, Krall RC, Moddrelle DS, et al. Morphologic changes of the arterial wall during regression of experimental atherosclerosis. Circulation 1992; 86: I518.

42. Gupta M, Connolly AJ, Zhu BQ, et al. Quantitative analysis of progression and regression of atherosclerosis by intravascular ultrasound: Validation in a rabbit model Circulation 1992; 86:1-518.

43. Blackenhorn DH, Krausch DM. Reversal of atherosclerosis and sclerosis: The two components of atherosclerosis. Circulation 1989; 79:1-7.

44. Lesperance J, Hudon G, White GW, et al. Comparison by quantitative angiographic assessment of coronary stenoses of one view showing the severest narrowing to two orthogonal views. Am J Cardiol 1989: 64:462-465.

45. Honye J, Ashit J, Tobis JM, et al. Atherosclerotic plaque eccentricity: A comparison of angiography and intravascular ultrasound imaging. (abstract) Circulation 1991 64:II-701.

46. Kimura BJ, Fitzgerald PJ, Sudhir K, et al. Guidance of directional coronary atherectomy by intracoronary ultrasound imaging. Am Heart J 1992; 124:1365-1369.

47. Potkin BN, Roberts WC. Effects of percutaneous transluminal angioplasty on atherosclerotic plaque and relation of plaque composition and arterial size to outcome. Am J Cardiol 1988; 62:41-50.

48. Waller BF. Coronary balloon artery dissections: "The Good, the Bad and the Ugly". J Am Coll Cardiol 1992; 20:701-706.

49. Tenaglia AN, Buller CE, Kisslo KB, et al. Intracoronary ultrasound predictors of adverse outcomes after coronary artery interventions. J Am Coll Cardiol 1992; 20 $1385-1390$.

50. Fitzgerald PJ, Ports TA, Yock PG. Contribution of localized calcium deposits to dissection after angioplasty. An 
DI MARIO, ET AL.

observational study using intravascular ultrasound. Circulation 1992: 86:64-70.

51. Potkin BN. Keren G, Mintz GS, et al. Arterial response to balloon coronary angioplasty: An intravascular ultrasound study. J Am Coll Cardiol 1992: 20:942-951.

52. Honye J, Mahon DJ. Tobis JM. et al. Morphologicat effects of coronary balloon angioplasty in vivo assessed by intravascular ultasisound imaging. Circulation 1992: 85:1012-1025

53. Wilson RF. Johnson MR. Marcus ML. et al. The effect of coronary angioplasty on coronary flow reserve. Circulation 1988: 77:873-885

54. Serruys PW, Reiber JHC. Wijins W. el at. Assessment of percutaneous transluminal coronary angioplasty by quantitative coronary arteriography: Diameter vs densitometric area measurement. Am J Cardiol 1984: 54: $482-488$.

55. Whiting JS. Pfaff JM. Eigler NL. Advantages and limilations of videodensitometry in quantitative coronary angiography. In Reiber JHC. Serruys PW. eds. Quantitalive Coronary Arteriography. Dordrecht: Kluver Academic Publishers. 1991: 43-54.

56. Serruys PW. Rutsch W. Heyndrick x G. el al. Prevention of restenosis after percutaneous transluminal coronary angioplasty with thromboxane A2-receptor blockade: 4 randomized. double-blind, placebo-controlled study. (irculation 1991: 84:1568-1580.

57. Rosenfield K. Losordo DW. Isner JM. et al. Three-dimensional reconstruction of human coronary and peripheral arteries from images recorded during two-dimensional intravascular ultrasound examination. Circulation 1991: 84:1938-1956

58. Di Mario C. Wenguang L.. Linker DT. et al. Three-dimensional intracoronary ultrasound. Goals and practical problems. Int J Cardiat Imaging 1993: 6.3-77.

59. Rosenfield K. Kaufman J. Pieczek A. at al. Real-time three-dimensional reconstruction of intravascular ulirasound images of iliac arteries. Am J Cardsol 1992: 70: $4 ! 2-415$.

60. (oy KM Park JC. Fishbein MC et al In vitro validation of three-dimensional intravascular ultrasound for the evaluation of atterial injury after balloon angioplasty. J Am Coll Cardiol 1992: 20:692-7(K).

61. Cavaye DM. White RA. Lerman RD. el al. Usefulnes: of intravascular ult rasound imaging for detecting experimentally induced aortic dissection in dogs and for determining the effectiveness of endoluminal stenting. Am J Cardiol 1992: 69:705-707

62. Di Mario C. Madretsmal S. Roelandi IRTC. et al. Angledependency in intravascular uthasound. Am Heart J 1993; 125:992-998

63. Isner JM. Rusenfield K. Losordo DW. et al. Combination balloon-ultrasound imaging catheter for percutane- ous transluminal angioplasty. Circulation 1991: 84: 739-754.

64. Hodgson J. Cacchione J. Reddy K, et al. Combined coronary angioplasty balloon and ultrasound catheter: Preliminary findings. (abstract) Eur Heart J 1991; 12:381.

65. Reiber JHC. An overview of coronary quantitation techniques as of 1989. In: Reiber JHC. Serruys PW, eds. Quantitative Coronary Arteriography. Dordrecht, Kluver Academic Publishers, 1991;55-132.

66. Wenguang L. Gussenhoven WJ, Di Mario C, et al. Validation of quantitative analysis of intravascular ultrasound images. Int J Cardiac Imag 1991: 6:247-254

67. Wenguang L. Gussenhoven EJ. Bom N. et al. Frameto-frame assessment of arterial distensibility using a computerized semiautomatic program. Computers in Cardiology 1993: 333-336.

68. Vogel R. LeFree M. Bates E. et al. Application of digital techniques to selective coronary arteriography: Use of myocardial appearance time to measure coronary flow reserve. Am Heart J 1984: 107:153-164.

69. Zijlstra F. Reiber JHC. Serruys PW, et al. Which cineangiographically assessed anatomic variable correlates besi with functional measurements of stenosis severity? A comparison of quantitative analysis of the coronary angiogram with measured coronary flow reserve and exercise/redistribution Thallium 201 scintigraphy. J Am Coll Cardiol 1988: 12:686-691.

70. Pijls NHJ, van Leeuwen K. Uijen GJH, et al. The concept of maximal flow ratio for immediate evaluation of percutaneous transluminal coronary angioplasty. Circulation 1991: 83:854-86.5.

71. Graynburn PA. Willard JE. Donald RH, et al. Measurement of coronary flow using high-frequency intravascular ultrasound imaging and pulsed Doppler velocimetry. (abstract) J Am Coll Cardiol 1991; 6:234A.

72. Linker DT. Torp H. Angelsen AJ. et al. Instantaneous arterial flow estimated with an ultrasound imaging and Doppler catheter. (abstract) Circulation 1989: 80:11-580.

73. Doucette JW. Corl PD. Payne HM. el al. Validation of a Doppler guide-wire for intravascular measurement of coronary artery flow velocity. Circulation 1992: 85: $1899-1911$.

74. Kaufman J. Rosenfield K. Isner J, et al. Combined intravascular ultrasound and intravascular Doppler wire provide complementary anatomic and physiologic imaging during percutaneous revascularization. (abstract) J Am Coll Cardiol 1992: 19:293A.

75. Sudhir K. Macgregor JS. Yock PG, et al. Simultaneous intravascular two-dimensional and Doppler ultrasound. A new technique for in vivo assessment of coronary flow and vascular dynamics. J Am Coll Cardiol 1992: 19: $140 \mathrm{~A}$. 